\title{
Pharmacoeconomic assessment and comparing efficacy between cetirizine, levocetirizine, loratadine and fexofenadine in allergic rhinitis patients
}

\author{
Ganesh S. Pentewar*, Ranjit J. Wagh, Aparna S. Chincholkar
}

Department of Pharmacology, MIMER Medical College, Talegaon, Dabhade, Maharashtra, India

Received: 09 September 2017 Accepted: 03 October 2017

\section{*Correspondence to: Dr. Ganesh S. Pentewar, Email: drpentewarganesh@ gmail.com}

Copyright: (C) the author(s), publisher and licensee Medip Academy. This is an openaccess article distributed under the terms of the Creative Commons Attribution NonCommercial License, which permits unrestricted noncommercial use, distribution, and reproduction in any medium, provided the original work is properly cited.

\begin{abstract}
Background: A successful treatment of allergic rhinitis is considered not only as relief from sneezing, itching, rhinorrhoea, congestion but also as the functional impact on the patient's daily life. The cost of treating allergic rhinitis and indirect costs related to loss of workplace productivity are substantial.

Methods: The present study was single centered, open label, randomized, four Arm, parallel-group, comparative clinical study between orally administered Cetirizine, Levocetirizine, Loratadine and Fexofenatidine in patients with allergic rhinitis conducted at MIMER Medical college and Dr. Bhausaheb Sardesai hospital in rural Maval Taluka in Pune district of Maharashtra State.

Results: Total Nasal Symptom Score differs significantly for all the treatment groups. Subsequent pairwise contrasts using a Bonferroni adjustment reveals maximum reduction of symptoms in Levocetirizine group. Cost effectiveness ratio was effective for Levocetirizine followed by Cetirizine, Loratadine, and Fexofenadine.

Conclusions: From the analysis of results, the study shows that both Levocetirizine and Cetirizine control the symptoms of allergic rhinitis better as compared to Loratadine and Fexofenadine but Levocetirizine was a better choice in comparison to others due to its cost effectiveness.
\end{abstract}

Keywords: Allergic rhinitis, Cetirizine, Fexofenadine, Loratadine, Levocetirizine, Pharmacoeconomic assessment, Total nasal symptom score

\section{INTRODUCTION}

Allergic rhinitis (AR) is an inflammatory disease of the nasal mucosa induced by an allergen. The disorder is clinically characterized by nasal itching, sneezing, nasal congestion or stuffiness and rhinorrhea or runny nose that are reversible either spontaneously or as a result of treatment. AR is a global health problem, with a prevalence of between $9-42 \%$ among the general population. In India allergic rhinitis is the commonest form of allergy and constitutes more than $50 \%$ of all allergies seen in clinical practice. ${ }^{1-3}$ Medicines are the most common therapeutic intervention and form a small but significant proportion of total health care cost. Cost of medicines are growing constantly due to the availability of patented new drugs, preference of drug therapy over invasive therapy, discovering various off label uses of existing drugs and the irrational drug prescription. ${ }^{4}$ The direct cost of treating allergic rhinitis and the indirect cost related to loss of workplace productivity resulting from the disease are substantial. Rhinitis is also a significant cause of lost school attendance. Patients are affected by the high pricing of drugs and though the symptoms improve, the poor patient's compliance sets in if the regimen is heavy on the pocket. ${ }^{5,6}$ Knowledge of the concepts of pharmacoeconomics are therefore essential for physicians to prescribe individualized drug therapy based on essential drug concept i.e. STEP (suitability, tolerance, efficacy and 
price of the drug ) as well as rational utilization of the drug (RUD) criteria, with minimal costs to improve the costeffectiveness of the drug therapy. ${ }^{7}$ The present study is aimed to compare the efficacy and cost effectiveness between the four most common orally used second generation antihistaminics, viz. Cetirizine, Levocetirizine, Loratadine, Fexofenadine. $^{8}$

\section{METHODS}

The present study was single centered, open label, Randomized, Four Arm, parallel-group, comparative clinical study between orally administered Cetirizine, Levocetirizine, Loratadine and Fexofenatidine in patients with Allergic Rhinitis (AR) conducted at MIMER Medical college and Dr. Bhausaheb Sardesai hospital in rural Maval Taluka in Pune district of Maharashtra State.

\section{Enrollment}

The study was approved by Institutional Ethical Committee. Patients diagnosed as AR were identified from the ear nose and throat out patient department (ENT OPD). Once identified, they were briefed about the study and activities.

If they were apparently willing to take part in the study, a copy of a patient information sheet and informed consent form was given to patient. A copy of the patient diary was issued to patient and asked them to record nasal symptoms as per instruction.

\section{Inclusion criteria}

Patients were ought to meet all of the inclusion criteria.

- Patient with a clinical history of AR.

- Patients aged above 18 years inclusive of either sex.

- $\quad$ The combined score of Total nasal symptoms score (TNSS) (nasal congestion, rhinorrhea, nasal itching, sneezing) sum of morning and evening symptom score must be at least 8 and nasal congestion severity score (NCS) sum of morning and evening congestion score must be at least 3 at screening. ${ }^{9}$

- $\quad$ Patient with ability to understand and sign written informed consent form.

- Patients willing to comply with the protocol requirements.

\section{Exclusion criteria}

- Known hypersensitivity to antihistaminics.

- Alcohol or drug dependence.

- Concomitant medications that could affect the efficacy of study drugs.

- Clinically significant nasal disease (other than AR) or significant nasal structural abnormalities including nasal polyps; clinically relevant respiratory tract malformations; recent nasal biopsy (within 2 months); nasal trauma; nasal surgery; atrophic rhinitis.

- Asthma requiring chronic use of inhaled or systemic corticosteroids, routine use of beta- 2 agonists.

- $\quad$ Respiratory tract infection or disorder within 2 weeks of the first visit or a respiratory tract infection during first visit;

- Antibiotics for acute conditions within 2 weeks of the first visit.

- Pregnant or lactating women.

- Psychiatric illness.

- Topical corticosteroids in concentrations in excess of $1 \%$ hydrocortisone for dermatological conditions within 1 month of study initiation.

\section{Randomization}

A total of 52 patients (13 per each group) were assigned sequentially to each of the 4 study groups.

All the study patients received their respective medication orally daily in the evening for 1 week period.

- Group A- Tab Cetirizine Hydrochloride 10mg

- Group B- Tab Levocetirizine Hydrochloride 5mg

- $\quad$ Group C- Tab Loratadine 10mg

- Group D- Tab Fexofenadine Hydrochloride 120mg

Visit 1: Baseline screening and randomization to study treatment group (day 1)

Following procedures were performed on the first day of the subject enrolment:

1. Medical history

2. Physical Examination and Vital signs

3. Patient recording in patient diary (Morning Nasal symptoms score at the time of visit and evening Nasal symptoms score just before administration of antihistaminics)

4. Issue of study medications for 1 week treatment.

\section{Visit 2: End of study (day 8)}

Following procedures were performed on the eighth day:

1. Physical Examination and Vital signs

2. Checking for Patient's recording in patient diary (Nasal symptoms score)

\section{Efficacy assessment}

Patients were provided with Patient's Diary. This was filled by patient in the morning at the time of screening and randomization visit and in the evening (immediately before study drug administration) to obtain the baseline and daily Total Nasal Symptom Score for next 7 days. 
Nasal symptoms

- Nasal Congestion

- Rhinorrhea

- Nasal itching

- $\quad$ Sneezing

Each of the above symptoms was rated on a 4-point scale as follows:

Score grade description:

- $\quad 0$ None (No sign /Symptom evident);

- 1 Mild (Sign/ Symptoms clearly present, but minimal awareness; easily tolerated);

- 2 Moderate (Definite awareness of sign / Symptoms that is bothersome but tolerable);

- 3 Severe (Sign / Symptoms that is hard to tolerate; causes interference with activities of daily living and / or sleeping).

\section{Efficacy variable}

1. Mean change in Total Nasal Symptom Score (sum of scores of Nasal Congestion, Rhinorrhea, Itching and Sneezing) from Baseline to End of treatment.

2. Mean change in Total Nasal symptom score $=$ End of treatment score [(Morning TNSS average Day 2 (next morning after first dose) - Day 8) + (Evening TNSS average Day 2- Day 8)] - Baseline visit score [(Morning TNSS of Baseline visit) + (Evening TNSS of Baseline visit prior to first dose)]

3. Cost effectiveness analysis; e.g. drug A and drug B. ${ }^{10,11}$

Cost-effectiveness ratio $(\mathrm{CER})=$ Cost $_{\mathrm{A}} /$ Effect $_{\mathbf{A}}(\mathrm{Net}$ Cost/ Net Health Benefit)

Incremental cost-effectiveness ratio $($ ICER $)=$ Cost $\mathbf{A}-$ Cost $\mathbf{\text { }}$ / Effect $\mathbf{A}-$ Effect $_{\mathbf{B}}$

\section{Concomitant interventions}

No treatment for allergic rhinitis other than study medication was allowed during course of treatment. If rescue medications were required during study, such patients have to be excluded from study.

\section{Adherence assessment}

Compliance to study medication and patient diary entries were strictly verified during follow-up visit. The patients received the drugs from our institutional medical store.

\section{Statistical analysis}

Statistical analysis was performed by using Statistical Package for the Social Sciences SPSS 19.0. (SPSS Inc. Chicago, USA).
Data was summarized using Mean, Median and Standard Deviation.

'Paired 't' test was used to compare Mean changes in patients before and after treatment.

Probability $<0.05$ was considered statistically significant.

Analysis of variance was used to compare treatment groups for the quantitative primary and secondary outcomes.

In case of significant results, subsequent pairwise contrasts using a Bonferroni adjustment were made between the treatment groups. The statistician was blinded to the groups during analysis.

\section{RESULTS}

A total of 52 patients, 13 in each groups of the age group 18 to 65 years (Mean age $33.73 \pm 10.23$ years); $48.08 \%$ Females and $51.92 \%$ Males were randomized and received either Cetirizine, Levocetirizine, Loratadine, or Fexofenadine over a period of one week. Mean compliance with treatment was $100 \%$ for all four treatment groups. The baseline demographic data and clinical characteristics of all 52 patients participated in this study have been compared in the (Table 1).

\section{Average cost-effectiveness calculations}

\section{Noncompeting choice}

Noncompeting choice cost effectiveness has been done because in this study many possible options to choose from that are not mutually exclusive. Noncompeting choice cost effectiveness uses the average cost effectiveness by dividing the cost of the intervention by the benefit of the intervention.

The average cost effectiveness $=$ Net Cost (Rupees ₹) /

Net Health Benefit $=₹ /$ Mean change in TNSS $(\%)$

The average cost effectiveness of intervention for

Cetirizine $=$ Net Cost $/$ Net Health Benefit $=₹ 26.25 /$

$0.5075=51.73 / \%$ effect

Using this same means of calculation, the average cost effectiveness for intervention of Levocetirizine was ₹ 47/ $\%$ effect, Loratadine was ₹ 69.40/ \% effect and for Fexofenadine was ₹ $144.57 / \%$ effect (Table 2, Table 3 and Table 4).

\section{DISCUSSION}

The demographic characteristics of the study participants and the baseline symptom scores viz. Total Nasal Symptom Score (TNSS), Nasal Congestion Score prior to dosing were comparable among the four treatment groups (Table 1). 
Table 1: Comparison of demographic data and clinical characteristics of the patients participated in the study (n=52).

\begin{tabular}{|c|c|c|c|c|c|c|}
\hline Parameters & $\begin{array}{l}\text { Cetirizine } \\
\mathrm{n}=\mathbf{1 3}\end{array}$ & $\begin{array}{l}\text { Levocetirizine } \\
\mathrm{n}=13\end{array}$ & $\begin{array}{l}\text { Loratadine } \\
\mathrm{n}=13\end{array}$ & $\begin{array}{l}\text { Fexofenadine } \\
\mathrm{n}=13\end{array}$ & $\mathbf{F}$ & $\mathbf{p}^{*}$ \\
\hline Age (years) & $31.85 \pm 9.45$ & $39.38 \pm 14.39$ & $32 \pm 1.011$ & $31.69 \pm 7.22$ & 1.858 & 0.149 \\
\hline Male (\%) & $6(46.16 \%)$ & $4(30.77 \%)$ & $7(53.84 \%)$ & $10(76.92 \%)$ & & \\
\hline Sex Female (\%) & $7(53.84 \%)$ & $9(69.23 \%)$ & $6(46.16 \%)$ & $3(23.08 \%)$ & & \\
\hline TNSS & $12 \pm 1.22$ & $10.77 \pm 1.48$ & $10.92 \pm 1.44$ & $10.69 \pm 1.25$ & 0.461 & 0.635 \\
\hline NCS & $4.46 \pm 0.66$ & $3.87 \pm 0.68$ & $4 \pm 0.82$ & $4.15 \pm 0.55$ & 1.905 & 0.141 \\
\hline
\end{tabular}

Table 2: Comparison of Total Nasal Symptom Score (TNSS) before and after treatment.

\begin{tabular}{|llllll|}
\hline \multirow{2}{*}{ Groups $(\mathbf{n = 1 3})$} & Total nasal symptom score & & & \\
& Baseline score & End of treatment score & Mean change in score & t & p \\
\hline Cetirizine & $12 \pm 1.22$ & $5.90 \pm 0.62$ & $6.09 \pm 0.60$ & 27.18 & $<0.001 * *$ \\
\hline Levocetirizine & $10.77 \pm 1.48$ & $4.02 \pm 0.43$ & $6.75 \pm-1.04$ & 20.23 & $<0.001 * *$ \\
\hline Loratadine & $10.92 \pm 1.44$ & $4.64 \pm 0.60$ & $6.27 \pm 0.83$ & 22.87 & $<0.001 * *$ \\
\hline Fexofenadine & $10.69 \pm 1.25$ & $5.09 \pm 0.43$ & $5.59 \pm 0.81$ & 20.21 & $<0.001 * *$ \\
\hline F & 0.461 & 28.678 & & & \\
\hline p & 0.635 & $<0.0001 * * *$ & & & \\
\hline
\end{tabular}

The values are expressed as mean $\pm \mathrm{SD}, \mathrm{n}=13$ patient. $* *$ represents statistical significant of $\mathrm{p}<0.001$ when compared before and after treatment (Paired ' $\mathrm{t}$ ' test), $* * *$ significant at $\mathrm{p}<0.0001$ when compared between treatment groups using one-way analysis of variance (ANOVA) with post-hoc Bonferroni's test.

ANOVA comparison between groups $(<0.0001)$ i.e. TNSS differs significantly for all the treatment groups. Subsequent pairwise contrasts using a Bonferroni adjustment reveales maximum reduction in Levocetirizine group.

Table 3: Pharmacoeconomic assessments (cost effectiveness analysis) summary of Cost Effectiveness Ratio (CER).

\begin{tabular}{|c|c|c|c|c|}
\hline Methods & Cetirizine & Levocetirizine & Loratidine & Fexofenadine \\
\hline \multirow{4}{*}{$\begin{array}{l}\text { Method } 1 \\
\text { Cost consequence } \\
\text { Analysis (CCA) }\end{array}$} & \multicolumn{4}{|c|}{ Net Cost (at the end of 1 week treatment) } \\
\hline & $₹ 26.25$ & ₹ 29.46 & ₹ 39.84 & ₹ 75.58 \\
\hline & \multicolumn{4}{|c|}{ Net health benefit (\% mean change in TNSS) } \\
\hline & 50.75 & 62.67 & 57.41 & 52.29 \\
\hline $\begin{array}{l}\text { Method } 2 \\
\text { Average Cost } \\
\text { Effectiveness Ratios } \\
\text { (net cost/ net health benefit) }\end{array}$ & $\begin{array}{l}₹ 26.25 / 0.5075 \\
=₹ 51.73 \text { per cure }\end{array}$ & $\begin{array}{l}₹ 29.46 / 0.6267 \\
=₹ 47 \text { per cure }\end{array}$ & $\begin{array}{l}₹ 39.84 / 0.5741 \\
=₹ 69.40 \text { per cure }\end{array}$ & $\begin{array}{l}₹ 75.58 / 0.5229 \\
=₹ 144.54 \text { per cure }\end{array}$ \\
\hline
\end{tabular}

Table 4: Average cost effectiveness ratio.

\begin{tabular}{|llcl|}
\hline Intervention & $\begin{array}{l}\text { Net health benefit } \\
\text { mean change in TNSS (\%) }\end{array}$ & $\begin{array}{l}\text { Net cost } \\
\text { cost / 7 Tab (Rupees) }\end{array}$ & $\begin{array}{l}\text { A verage cost effectiveness ratio } \\
\text { (₹ / \% effect) }\end{array}$ \\
\hline Levocetirizine & 62.67 & $₹ 29.46$ & $₹ 47 / \%$ effect \\
\hline Cetirizine & 50.75 & $₹ 26.25$ & $₹ 51.73 / \%$ effect \\
\hline Loratadine & 57.41 & $₹ 39.84$ & $₹ 69.40 / \%$ effect \\
\hline Fexofenadine & 52.29 & $₹ 75.58$ & $₹ 144.57 / \%$ effect \\
\hline
\end{tabular}

The mean TNSS was significantly reduced in all 4 study groups, Overall TNSS was reduced to $50.75 \%, 57.41 \%$ and $52.29 \%$ respectively in Cetirizine, Loratadine and Fexofenadine groups, where as it was reduced maximally in Levocetirizine group, i.e. 62.67\% (Table 2).

\section{Cost effectiveness analysis}

Noncompeting choice
Levocetirizine should be preferred because it has the lowest cost-effectiveness ratio compared to the other interventions (i.e. ₹ $47 / \%$ effect vs ₹ $51.73 / \%$ effect or ₹ $69.40 / \%$ effect or ₹ $144.57 / \%$ effect). This would be a more efficient way of spending money rather than starting with one of the other interventions that has a higher average cost-effectiveness ratio without any additional benefit (Table 3 and Table 4). 


\section{Competing choice}

In competing choice method of cost-effectiveness analysis, the incremental cost-effectiveness ratio (NOT average cost effectiveness) has been done. This would allow to determine the marginal or incremental cost for an additional unit of health benefit when choosing between different interventions. But in this study, there were no any additional health benefit by choosing Cetirizine, Loratadine and Fexofenadine vs Levocetirizine. so incremental cost-effectiveness ratio has not been done.

The results of this study corroborate with those of a previous study done by Ralph Mosges et al, in which monotherapy with Levocetirizine was found to be significantly more effective in lowering the Total Nasal Symptom Score than the Desloratadine and Fexofenadine alone or in combination with intranasal corticosteroids. A meta-analysis has illustrated greater effectiveness for treatment with the active substance levocetirizine as monotherapy in reducing allergic symptoms when compared to treatment with Loratadine. ${ }^{12}$ Ciprandi $\mathrm{G}$ et al, in a pilot study demonstrated the effectiveness of levocetirizine in: (i) relieving nasal symptoms, (ii) improving nasal airflow, (iii) reducing leucocyte infiltration, and (iv) diminishing cytokine levels. ${ }^{13}$ Friedrich Horak et al, evaluated Levocetirizine was more effective than fexofenadine at and later than 22 hours after drug intake, an indication of the longer-duration of action of levocetirizine. ${ }^{14}$ Stubner $\mathrm{P}$ et al, study also concluded that Levocetirizine was superior to loratadine in improving symptoms in seasonal AR and that there was a similar trend in perineal AR. ${ }^{15}$

The findings were consistent across the literature, suggesting Levocetirizine improved outcomes, leading to incremental cost savings and cost-effectiveness. ${ }^{16}$ Anthi Rogkakou et al, concluded that Levocetirizine was welltolerated, safe, and suitable for continuous and longlasting treatment. Furthermore, a long-term treatment with Levocetirizine reduces overall costs (direct and indirect costs) for both persistent allergic rhinitis and associated comorbidities, with a consequently important impact on socioeconomic aspects. ${ }^{17-19}$

\section{CONCLUSION}

The present study was carried out in the patients of Allergic Rhinitis, visiting the ENT OPD at a tertiary care hospital in the rural areas of Maval Taluka of Pune District, Maharashtra. Nasal symptoms were assessed by Total Nasal Symptom Score and pharmacoeconomic assessment by cost effectiveness analysis. Cetirizine did not prove any superior to other antihistaminics in clinical efficacy but it was equally effective in controlling the nasal congestion. Levocetirizine appears to be statistically significantly effective and offers relief from almost all of the individual nasal symptoms viz. nasal congestion, rhinorrhea, itching, and sneezing within a week and TNSS. Levocetirizine was a rapidly and sustainably effective antihistaminic for the treatment of AR and most cost effective when evaluated with pharmacoeconomic criteria such as cost effectiveness analysis.

\section{ACKNOWLEDGEMENTS}

Authors would like to thank to Dr. Ghaisas Virendra, Professor and Head of the department, Dr. Khan Mubarak, Dr. Parab Sapana, Dr. Mane Santosh the faculty at the Department of ENT for allowing them to conduct study. Also, would like to thank to Mrs. Raje Swati, Assistant Professor, Department of Community Medicine who has provided valuable input for statistical and pharmacoeconomic analysis.

Funding: No funding sources

Conflict of interest: None declared

Ethical approval: The study was approved by the Institutional Ethics Committee

\section{REFERENCES}

1. Shah A, Pawankar R. Allergic rhinitis and co-morbid asthma: perspective from India-ARIA Asia-Pacific Workshop report. Asian Pacific journal of allergy and immunology. 2009 Mar 1;27(1):71.

2. Bousquet J, Khaltaev N, Cruz AA, Denburg J, Fokkens WJ, Togias A, et al. Allergic rhinitis and its impact on asthma (ARIA). Allergy. 2008 Apr $1 ; 63(\mathrm{~s} 86): 8-160$.

3. Bauchau V, Durham SR. Epidemiological characterization of the intermittent and persistent types of allergic rhinitis. Allergy. 2005 Mar 1;60(3):350-3.

4. Scarupa MD, Michael A. Kaliner Inflammatory Nature of Allergic Rhinitis: Pathophysiology. Medscape Allergy \& Immunology. 2006;6(1).

5. Hay JW, Kaliner MA. Costs of second-generation antihistamines in the treatment of allergic rhinitis: US perspective. 2009 Jun; 25(6):1421-31.

6. Hay JW, Leahy M. Cost and Utilization Impacts of Oral Antihistamines in the California Medi-Cal Program. Value in Health. 2005;8:506-16.

7. Kulkarni U, Dalvi K, Moghe VV, Deshmukh YA. Pharmacoeconomics: An emerging branch in health sciences for decision making. African Journal of Pharmacy and Pharmacology. 2009 Aug 31;3(8):3627.

8. Goodman and Gilman's. The Pharmacological Basis of Therapeutics, 12 ${ }^{\text {th }}$ Ed. China: Mc Graw Hill companies; 2011:920.

9. Maiti R, Jaida J, Rahman J, Gaddam R, Palani A. Olopatadine hydrochloride and rupatadine fumarate in seasonal allergic rhinitis: A comparative study of efficacy and safety. Journal of pharmacology \& pharmacotherapeutics. 2011 Oct;2(4):270.

10. Newby D, Hill S. Use of pharmacoeconomics in prescribing research. Part 2: cost minimization analysis - when are two therapies equal? J of Clinical Pharmacy and Therapeutics. 2003;28:145-50. 
11. Lopert R, Lang DL, Hill SR. Use of pharmacoeconomics in prescribing research. Part 3: cost-effectiveness analysis-a technique for decisionmaking at the margin. Journal of clinical pharmacy and therapeutics. 2003 Jun 1;28(3):243-9.

12. Mösges R, König V, Köberlein J. The effectiveness of modern antihistamines for treatment of allergic rhinitis-an IPD meta-analysis of 140,853 patients. Allergology International. 2013;62(2):215-22.

13. Ciprandi G, Cirillo I, Vizzaccaro A, Tosca MA. Levocetirizine improves nasal obstruction and modulates cytokine pattern in patients with seasonal allergic rhinitis: a pilot study. Clinical \& Experimental Allergy. 2004 Jun 1;34(6):958-64.

14. Horak F, Zieglmayer PU, Zieglmayer R, Kavina A, Lemell P. Levocetirizine has a longer duration of action on improving total nasal symptoms score than fexofenadine after single administration. British journal of clinical pharmacology. $2005 \mathrm{Jul}$ 1;60(1):2431.

15. Stübner $\mathrm{P}$, Zieglmayer R, Horak F. A direct comparison of the efficacy of antihistamines in SAR and PAR: randomised, placebo-controlled studies with levocetirizine and loratadine using an environmental exposure unit-the Vienna Challenge Chamber (VCC). Current medical research and opinion. 2004 Jun $1 ; 20(6): 891-902$.
16. Dubuske LM, Seal B, Brown MC. Pharmacoeconomics of levocetirizine in allergic rhinitis and chronic idiopathic urticaria: considerations for the USA. Expert Rev Pharmacoecon Outcomes Res. 2008 Jun;8(3):233-41.

17. Rogkakou A, Villa E, Garelli V, Canonica GW. Persistent allergic rhinitis and the XPERT study. World Allergy Organization Journal. 2011 Mar 15;4(3):S32.

18. Bachert C, Bousquet J, Canonica GW, Durham SR, Klimek L, Mullol J, et al. XPERT Study Group. Levocetirizine improves quality of life and reduces costs in long-term management of persistent allergic rhinitis. Journal of allergy and clinical immunology. 2004 Oct 31;114(4):838-44.

19. Lee CF, Sun HL, Lu KH, Ku MS, Lue KH. The comparison of cetirizine, levocetirizine and placebo for the treatment of childhood perennial allergic rhinitis. 2009;20(5):493-9.

Cite this article as: Pentewar GS, Wagh RJ,

Chincholkar AS. Pharmacoeconomic assessment and comparing efficacy between cetirizine, levocetirizine, loratadine and fexofenadine in allergic rhinitis patients. Int J Basic Clin Pharmacol 2017;6:2684-9. 